\title{
The effect of 'crystallinity' and structural disorder on the electrochemical performance of substituted nickel hydroxide electrodes
}

\author{
T. N. Ramesh • P. Vishnu Kamath
}

Received: 19 April 2008 / Accepted: 17 May 2008 / Published online: 27 June 2008

(C) Springer-Verlag 2008

\begin{abstract}
Nickel hydroxide exhibit non-uniform broadening reflections in their PXRD pattern due to the presence of structural disorder. $\beta_{\mathrm{bc}}$-Nickel hydroxide electrodes with smaller crystallite size and structural disorder reversibly exchanges $0.9 \mathrm{e} / \mathrm{Ni}$. $\mathrm{Co} / \mathrm{Zn} / \mathrm{Ca} / \mathrm{Cd}$-substituted $\beta_{\mathrm{bc}}$-nickel hydroxide samples also display nonuniform broadening of reflections in their powder X-ray diffraction patterns with smaller crystallite size and exchanges $0.7-0.8 \mathrm{e} / \mathrm{Ni}$. Hydrothermal treatment of $\beta_{\mathrm{bc}^{-}}$ nickel hydroxide slurry at $170{ }^{\circ} \mathrm{C}$ results in an ordering of reflections in their powder X-ray diffraction pattern with an increased crystallite size. Crystalline $\beta$-nickel hydroxide electrode reversibly exchanges $0.3-0.4 \mathrm{e} / \mathrm{Ni}$. Hydrothermaltreated $\mathrm{Co} / \mathrm{Zn} / \mathrm{Ca} / \mathrm{Cd}$-substituted $\beta_{\mathrm{bc}}$-nickel hydroxide slurries at $170{ }^{\circ} \mathrm{C}$ display sharp reflections with similar crystallite size and electrochemical activities as that of crystalline $\beta$-nickel hydroxide. This clearly demonstrates that partial substitution of $\mathrm{Co} / \mathrm{Zn} / \mathrm{Ca} / \mathrm{Cd}$ in the nickel hydroxide matrix does not show any dramatic improvement in their electrochemical activity at $25-30{ }^{\circ} \mathrm{C}$. Structural disordered material with smaller crystallite size delivers electrochemical activity close to theoretical capacity.
\end{abstract}

Keywords Crystallinity · Substituted nickel hydroxide .

Structural disorder . Electrochemical activity

\section{Introduction}

Nickel hydroxide has drawn considerable attention of material chemists and battery technologists due to its

T. N. Ramesh $(\bowtie) \cdot$ P. Vishnu Kamath

Department of Chemistry, Central College, Bangalore University,

Bangalore 560 001, India

e-mail: adityaramesh77@yahoo.com functional use as a positive electrode material in all nickel-based alkaline secondary cells [1]. Depending on the preparative conditions under which the crystallization of nickel hydroxide from a solution is brought about, it can exist in polymorphic modifications, i.e., $\alpha$ and $\beta$. In addition to these two phases, badly crystalline phase of $\beta$ nickel hydroxide known as $\beta_{\mathrm{bc}}$ (bc, badly crystalline) nickel hydroxide has also been reported [2]. The polymorphic modifications of nickel hydroxide differ from one other in their structure, composition, and morphological features. All these phases derive their structure from brucite mineral $\left[\mathrm{Mg}(\mathrm{OH})_{2}\right]$. The structure of brucite comprises of hexagonal close packing of hydroxyl ions in which every alternate layers of octahedral sites are occupied by the divalent $\mathrm{Ni}^{2+}$ ions resulting in the stacking of charge neutral layers [3]. The interplanar spacing for $\beta$-phase is $4.6 \AA$, and $\alpha$-phase is $7.6 \AA$. Water molecules and anions present in the interlamellar gallery of $\alpha$-phase results in an increase in the d-spacings.

Bode and coworkers have reported two redox couples $\beta /$ $\beta$ couple and $\alpha / \gamma$ couple for the two different phases of nickel hydroxide [4]. The $\beta / \beta$ couple in nickel hydroxide can be written as

$\beta-\mathrm{Ni}(\mathrm{OH})_{2}+\mathrm{OH}^{-} \leftrightarrow \beta-\mathrm{NiOOH}+\mathrm{H}_{2} \mathrm{O}+e^{-}$

The redox reaction involves diffusion of protons during the charge-discharge process in nickel hydroxide. The electrochemical activities of the polymorphic modifications differs from one another due to the changes in their structure and composition. $\alpha$-Nickel hydroxide being a hydrated form of $\beta$-nikel hydroxide is expected to provide a good pathway for the diffusion of protons during the charge-discharge process. The factors that can affect the active material utilization are small particle size, poor 
crystallinity, high tap density, and high moisture content [58]. In addition to these factors, crystallographic faults such as stacking faults [9] and structural disorder [10] are also known to contribute to higher active material utilization, close to theoretical value. Several authors have reported that the active material utilization is better in substituted nickel hydroxide compared to unsubstituted nickel hydroxide samples. They use $\mathrm{Co}(\mathrm{OH})_{2} / \mathrm{Zn}(\mathrm{OH})_{2} / \mathrm{Ca}(\mathrm{OH})_{2} /$ $\mathrm{Cd}(\mathrm{OH})_{2}$ during the material synthesis and electrode fabrication to improve the electrochemical performance and to overcome the incomplete discharge process [11-13]. Substituted nickel hydroxide samples are known to alter the conductivity [14] and the oxygen evolution potential, thereby enhancing the better active material utilization during the discharge process [15]. Oshitani et al. and Tarascon et al. have extensively studied the effect of cobalt on the electrochemical performance and optimized the conditions where material delivers $>1 \mathrm{e}^{-}$exchange [16, 17]. Substituted nickel hydroxides are known to deliver better electrochemical performance at higher temperatures compared to that at $25-30{ }^{\circ} \mathrm{C}$ [18].

Some of the limitations in these studies are (1) the usage of commercial grade $\beta$-phase of nickel hydroxide in which the exact preparation conditions are not clearly known [19]; (2) the active material, by default, contains small percentages of zinc and cobalt, which in principle can affect the crystal structure as well as the electrochemical activity [20]; (3) powder diffraction pattern for these samples are not reported, which could have provided better insight into the electrochemical activity of these materials, whether it is actually due to the effect of additive/substituents or due to the presence of structural disorder and crystallite size effects [21]. Oshitani et al. [22] have also used lanthanum oxides as additives in nickel hydroxide and studied their charge-discharge process.

In most of the studies, the question remains unanswered; i.e., is it possible to significantly alter the electrochemical properties of the $\beta$-phase of nickel hydroxide by partial substitution of nickel by cobalt/zinc/calcium/cadmium? To the best of our knowledge there are no reports correlating the effect of precipitation conditions on the crystallite size effects and the line broadening of non-(hk0) reflections of substituted nickel hydroxide and its role on the electrochemical performance. In this paper, we report that the reversible discharge capacity of $\beta_{\mathrm{bc}}$-nickel hydroxide samples is associated with small crystallite size and structural disorder and not due the effect of substituents at $25-30{ }^{\circ} \mathrm{C} . \beta_{\mathrm{bc}}$-Nickel hydroxide with small crystallite size $(30 \times 245 \AA)$ delivers $0.9 \mathrm{e} / \mathrm{Ni}$, while substituted $\beta_{\mathrm{bc}}$-nickel hydroxides having similar crystallite sizes also deliver close to $0.7-0.8$ e exchange. Highly ordered crystalline $\beta$-nickel hydroxide with crystallite size $(674 \times 458 \AA)$ delivers $0.4 \mathrm{e} /$ $\mathrm{Ni}$, while crystalline phases of cobalt/zinc/calcium/cadmi- um-substituted $\beta$-nickel hydroxide samples prepared by hydrothermal treatment of the slurries at $170{ }^{\circ} \mathrm{C}$ (crystallite size $-528 \times 679 \AA$ ) delivers $0.4 \mathrm{e} / \mathrm{Ni}$ with no improvement in their electrochemical activities. This clearly indicates that better electrochemical activity is associated to small crystallite size of a structural disordered material.

\section{Experimental section}

\section{Synthesis}

Nickel hydroxide was prepared by the addition of nickel nitrate solution $(50 \mathrm{ml}, 1 \mathrm{M})$ to $\mathrm{NaOH}(100 \mathrm{ml}, 2 \mathrm{M})$ at $80^{\circ} \mathrm{C}$ under constant stirring [6]. The obtained green slurry was divided into two parts: One part of the slurry was aged in mother liquor at $65{ }^{\circ} \mathrm{C}$ for $18 \mathrm{~h}$ to obtain the badly crystalline $\beta_{\mathrm{bc}}$-nickel hydroxide, and the other part of the slurry was hydrothermally treated $\left(170{ }^{\circ} \mathrm{C}\right.$ for $18 \mathrm{~h} ; 50 \%$ filling) to obtain highly ordered crystalline phase of $\beta$ nickel hydroxide with improved crystal growth.

Substituted nickel hydroxide samples were prepared by the addition of mixed metal nitrate solutions $\left[\mathrm{Ni}\left(\mathrm{NO}_{3}\right)_{2}\right.$ and $\mathrm{M}\left(\mathrm{NO}_{3}\right)_{2}$, where $M=\mathrm{Co}, \mathrm{Zn}, \mathrm{Cd}$, and $\mathrm{Ca}$; mole ratio, $0.95: 0.05,0.90: 0.1,0.85: 0.15$, and $0.8: 0.2]$ to $\mathrm{NaOH}$ $(100 \mathrm{ml}, 2 \mathrm{M})$ at $80{ }^{\circ} \mathrm{C}$ under constant stirring. The green slurry obtained was divided into two parts: One part of the slurry was aged in mother liquor at $65^{\circ} \mathrm{C}$ for $18 \mathrm{~h}$ to obtain the substituted $\beta_{\mathrm{bc}}$-nickel hydroxides, and the other part of the slurry was hydrothermally treated at $170{ }^{\circ} \mathrm{C}$ for $18 \mathrm{~h}$ ( $50 \%$ filling) to obtain highly ordered substituted crystalline $\beta$-nickel hydroxide samples. The products were washed with distilled water till free of alkali and dried at $65{ }^{\circ} \mathrm{C}$ to constant weight.

\section{Characterization}

The samples were characterized by X-ray powder diffraction using a Siemens D5005 powder X-ray diffractometer; data was collected with a $\mathrm{Cu} \mathrm{K} \alpha$ source (Ni filter, $\lambda=$ $1.541 \AA$ ) and infrared spectroscopy (Nicolet Impact 400D FTIR spectrometer, $\mathrm{KBr}$ pellets, $4 \mathrm{~cm}^{-1}$ resolution). Isothermal weight loss studies were carried out by decomposing the sample at $800{ }^{\circ} \mathrm{C}$ for $2 \mathrm{~h}$. Reversible moisture content was estimated as described elsewhere [8], and the elemental analysis was carried out using energy-dispersive $\mathrm{X}$-ray analysis. The chemical composition, total weight loss, and reversible moisture content of all the samples are given in Tables 1 and 2 within $1 \mathrm{wt} \%$ error. Crystallite size of all nickel hydroxide samples was estimated using the Scherrer formula. Crystallite thickness was calculated from (001) reflection, while disc diameter from (110) reflection. In Table 3 are given the values of crystallite size. Table 4 
Table 1 Results of wet chemical analysis of the substituted $\beta_{\mathrm{bc}}$-nickel hydroxide samples prepared at $80{ }^{\circ} \mathrm{C}$

\begin{tabular}{|c|c|c|c|c|c|c|c|}
\hline \multirow[t]{2}{*}{ Sample $\mathrm{Ni}_{1-x} \mathrm{M}_{x}(\mathrm{OH})_{2}$} & \multicolumn{4}{|c|}{ Weight percentage } & \multirow[t]{2}{*}{ Approximate formula } & \multirow[t]{2}{*}{ Reversible moisture content (wt $\%$ ) } & \multirow[t]{2}{*}{ Weight loss $(\%)^{\mathrm{a}}$} \\
\hline & $\mathrm{Ni}^{2+}$ & $\mathrm{M}^{2+}$ & $\mathrm{OH}^{-}$ & $\mathrm{H}_{2} \mathrm{O}$ & & & \\
\hline$\beta_{\mathrm{bc}}$-nickel hydroxide & 53.8 & - & 31.2 & 14.8 & $\mathrm{Ni}(\mathrm{OH})_{2} \cdot 0.9 \mathrm{H}_{2} \mathrm{O}$ & 12 & $30.1(31.4)$ \\
\hline $\mathrm{Co}_{0.06}$ & 56.3 & 2.5 & 36.8 & 8.2 & $\mathrm{Ni}_{0.96} \mathrm{Co}_{0.04}(\mathrm{OH})_{2} \cdot 0.3 \mathrm{H}_{2} \mathrm{O}$ & 11.5 & $27.6(28.2)$ \\
\hline $\mathrm{Co}_{0.12}$ & 51.6 & 7.0 & 31.7 & 7.8 & $\mathrm{Ni}_{0.88} \mathrm{Co}_{0.12}(\mathrm{OH})_{2} \cdot 0.44 \mathrm{H}_{2} \mathrm{O}$ & 9.4 & $27.3(25.8)$ \\
\hline $\mathrm{Co}_{0.26}$ & 42.2 & 15.6 & 33.0 & 10.8 & $\mathrm{Ni}_{0.74} \mathrm{Co}_{0.26}(\mathrm{OH})_{2} \cdot 0.6 \mathrm{H}_{2} \mathrm{O}$ & 11.0 & $(27.4)$ \\
\hline $\mathrm{Zn}_{0.15}$ & 49.8 & 9.8 & 33.4 & 6.4 & $\mathrm{Ni}_{0.96} \mathrm{Co}_{0.04}(\mathrm{OH})_{2} \cdot 0.3 \mathrm{H}_{2} \mathrm{O}$ & 4.6 & $25.6(24.3)$ \\
\hline $\mathrm{Zn}_{0.17}$ & 48.7 & 11.1 & 33.9 & 6.2 & $\mathrm{Ni}_{0.83} \mathrm{Zn}_{0.17}(\mathrm{OH})_{2} \cdot 0.3 \mathrm{H}_{2} \mathrm{O}$ & 3.4 & $25.4(26.4)$ \\
\hline $\mathrm{Ca}_{0.06}$ & 55.7 & 2.4 & 34.3 & 7.4 & $\mathrm{Ni}_{0.94} \mathrm{Ca}_{0.06}(\mathrm{OH})_{2} \cdot 0.4 \mathrm{H}_{2} \mathrm{O}$ & 11.3 & $27.1(25.7)$ \\
\hline $\mathrm{Cd}_{0.06}$ & 53.1 & 5.6 & 32.4 & 9.4 & $\mathrm{Ni}_{0.95} \mathrm{Cd}_{0.05}(\mathrm{OH})_{2} \cdot 0.53 \mathrm{H}_{2} \mathrm{O}$ & 11.4 & $23.3(22.6)$ \\
\hline
\end{tabular}

${ }^{\text {a }}$ Values in parentheses are calculated on the basis of the approximate formula.

gives the full width at half maxima $\left(\mathrm{FWHM} \pm 0.1^{\circ} 2 \theta\right)$ values of all the reflections of nickel hydroxide samples.

PXRD simulation studies

The PXRD patterns of $\beta_{\mathrm{bc}}$-nickel hydroxide obtained at $80^{\circ} \mathrm{C}$ and crystalline $\beta$-nickel hydroxide prepared at $170{ }^{\circ} \mathrm{C}$ were simulated using DIFFaX code, and the details are reported elsewhere [23].

\section{Electrochemical studies}

The charge-discharge studies of all the electrodes were carried out by mixing the active material, graphite powder, and polytetrafluoroethylene suspension (33\%) in the weight ratio of 0.6:0.3:0.1 and thoroughly ground to a paste-like consistency. This paste was pressed onto nickel foam $(2.9 \times$ $2.3 \mathrm{~cm}$ ) at a pressure of $90-120 \mathrm{~kg} \mathrm{~cm}^{-2}$ at $25-30^{\circ} \mathrm{C}$. The electrodes were dried at $65{ }^{\circ} \mathrm{C}$ to constant weight and then soaked in $6 \mathrm{M} \mathrm{KOH}$ solution for $24 \mathrm{~h}$ and galvanostatically charged to $120 \%$ of the theoretical capacity of the active material. Nickel plate counters were used for cycling, and all potentials were measured using a $\mathrm{Hg} / \mathrm{HgO} / \mathrm{OH}^{-}$(6 M $\mathrm{KOH})$ reference. The electrodes were discharged at approximately $\mathrm{C} / 2$ rate to a cutoff voltage of $0 \mathrm{~V}$ at $28-30^{\circ} \mathrm{C}$. Discharge capacities were normalized with respect to the weight of the active material. To study the oxygen evolution potentials and the half discharge potentials, the electrodes were charged at $\mathrm{C}$ rate and discharged at $\mathrm{C} / 2$ rate. Two electrodes of each sample were cycled for reproducible behavior.

\section{Results and discussion}

Figure 1a shows the PXRD pattern of nickel hydroxide prepared by using strong alkali at $80^{\circ} \mathrm{C}$. We have examined the factors that can affect the reflections in the PXRD patterns of nickel hydroxide samples, and they are listed as follows:

1. Particle size [5]

2. Cation vacancies $[24,25]$

3. Stacking faults [26]

4. Turbostraticity [27]

5. Interstratification [28]

6. Disorder in the arrangement of the intercalated species [29].

The reflections in the PXRD pattern of Fig. 1a exhibit excessive and nonuniform broadening of non-(hk0) reflections designated as $\beta_{\mathrm{bc}}$-nickel hydroxide. In Fig. $1 \mathrm{~b}$ is shown the PXRD pattern of nickel hydroxide obtained by hydrothermal treatment of nickel hydroxide slurry at $170{ }^{\circ} \mathrm{C}$ denoted as crystalline $\beta$-nickel hydroxide. The peak positions of all the Bragg reflections appear at similar

Table 2 Results of wet chemical analysis of substituted $\beta$-nickel hydroxide samples obtained on hydrothermal treatment at $170{ }^{\circ} \mathrm{C}$

\begin{tabular}{|c|c|c|c|c|c|c|c|}
\hline \multirow[t]{2}{*}{ Sample $\mathrm{Ni}_{1-x} \mathrm{M}_{x}(\mathrm{OH})_{2}$} & \multicolumn{4}{|c|}{ Weight percentage } & \multirow[t]{2}{*}{ Approximate formula } & \multirow[t]{2}{*}{ Reversible moisture content (wt $\%$ ) } & \multirow[t]{2}{*}{ Weight loss $(\%)^{\mathrm{a}}$} \\
\hline & $\mathrm{Ni}^{2+}$ & $\mathrm{M}^{2+}$ & $\mathrm{OH}^{-}$ & $\mathrm{H}_{2} \mathrm{O}$ & & & \\
\hline$\beta$-Nickel hydroxide & 61.7 & - & 31.4 & 2.4 & $\mathrm{Ni}(\mathrm{OH})_{2} \cdot 0.1 \mathrm{H}_{2} \mathrm{O}$ & 3.6 & $21.6(21.4)$ \\
\hline $\mathrm{Co}_{0.05}$ & 56.3 & 2.5 & 36.7 & 8.2 & $\mathrm{Ni}_{0.96} \mathrm{Co}_{0.04}(\mathrm{OH})_{2} \cdot 0.3 \mathrm{H}_{2} \mathrm{O}$ & 4 & $23.3(22.6)$ \\
\hline $\mathrm{Zn}_{0.17}$ & 51.9 & 11.1 & 36.2 & - & $\mathrm{Ni}_{0.83} \mathrm{Zn}_{0.17}(\mathrm{OH})_{2}$ & - & $18.4(19.1)$ \\
\hline $\mathrm{Cd}_{0.05}$ & 58.4 & 5.6 & 35.6 & - & $\mathrm{Ni}_{0.95} \mathrm{Cd}_{0.05}(\mathrm{OH})_{2}$ & 3 & $18.2(18.8)$ \\
\hline
\end{tabular}

${ }^{a}$ Values in parentheses are calculated on the basis of the approximate formula. 
Table 3 crystallite sizes of substituted $\beta_{\mathrm{bc}}$-nickel hydroxide samples

\begin{tabular}{lcc}
\hline Sample & $\begin{array}{l}\text { Thickness } \\
( \pm 0.06 \AA)\end{array}$ & $\begin{array}{l}\text { Disc diameter } \\
( \pm 0.4 \AA)\end{array}$ \\
\hline$\beta_{\mathrm{bc}}-\mathrm{Nickel} \mathrm{hydroxide}$ & 30 & 254 \\
$\beta_{\mathrm{bc}}-\mathrm{Ni}_{0.94} \mathrm{Co}_{0.06}(\mathrm{OH})_{2}$ & 31 & 149 \\
$\beta_{\mathrm{bc}}-\mathrm{Ni}_{0.82} \mathrm{Co}_{0.12}(\mathrm{OH})_{2}$ & 37 & 179 \\
$\beta_{\mathrm{bc}}-\mathrm{Ni}_{0.74} \mathrm{Co}_{0.26}(\mathrm{OH})_{2}$ & 39 & 245 \\
$\beta_{\mathrm{bc}}-\mathrm{Ni}_{0.85} \mathrm{Zn}_{0.15}(\mathrm{OH})_{2}$ & 51 & 216 \\
$\beta_{\mathrm{bc}}-\mathrm{Ni}_{0.83} \mathrm{Zn}_{0.17}(\mathrm{OH})_{2}$ & 32 & 225 \\
$\beta_{\mathrm{bc}}-\mathrm{Ni}_{0.82} \mathrm{Zn}_{0.18}(\mathrm{OH})_{2}$ & 51 & 216 \\
$\beta_{\mathrm{bc}}-\mathrm{Ni}_{0.94} \mathrm{Ca}_{0.06}(\mathrm{OH})_{2}$ & 30 & 149 \\
$\beta_{\mathrm{bc}}-\mathrm{Ni}_{0.94} \mathrm{Cd}_{0.06}(\mathrm{OH})_{2}$ & 39 & 151 \\
$(\mathrm{HT} 170) \beta-\mathrm{nickel}$ & 674 & 458 \\
$\mathrm{hydroxide}_{3-\mathrm{Ni}_{0.95} \mathrm{Co}_{0.05}(\mathrm{OH})_{2}}$ & 528 & 679 \\
$\beta-\mathrm{Ni}_{0.83} \mathrm{Zn}_{0.17}(\mathrm{OH})_{2}$ & 300 & 376 \\
$\beta-\mathrm{Ni}_{0.95} \mathrm{Cd}_{0.05}(\mathrm{OH})_{2}$ & 498 & 273 \\
\hline
\end{tabular}

$d$ values in both the samples. Interstratification is an intergrowth of $\alpha$-phase in $\beta$-nickel hydroxide. The presence of a small percent of $\alpha$-phase in $\beta$-nickel hydroxide contributes to the broadening non-(hk0) reflections in the PXRD pattern, resulting in disorder. When structural disorder gets incorporated in nickel hydroxide, bonding and the local coordination around the $\mathrm{Ni}^{2+}$ ion changes. Interstratification and cation vacancies mainly affect the composition as well as the coordination shell of nickel hydroxide. The composition and first coordination shell of $\beta$-nickel hydroxide is $\mathrm{Ni}(\mathrm{OH})_{6}$, where as for $\alpha$-nickel hydroxide, it is $\mathrm{Ni}(\mathrm{OH})_{6-x}\left(\mathrm{H}_{2} \mathrm{O}\right)_{x}$ or $\mathrm{Ni}(\mathrm{OH})_{6-x} \quad\left(\mathrm{NO}_{3}\right)_{x}$. Coordinatively, unsaturated $\beta_{\mathrm{bc}}$-nickel hydroxide phase assists in diffusion of protons, thereby enhancing conductivity of the material. Cation vacancies also changes the composition and coordination of nickel hydroxide from $\mathrm{Ni}$ $(\mathrm{OH})_{6}$ to $\left[\mathrm{Ni}_{1-x^{\prime} x}(\mathrm{OH})_{6-2 x}\left(\mathrm{H}_{2} \mathrm{O}\right)_{2 x}\right]$. Broadening of $(\mathrm{h} 0 \ell)$ reflections in the PXRD pattern of nickel hydroxide has been attributed to the presence of stacking faults. There are two types of stacking faults (growth faults and deformation faults) reported to be present in nickel hydroxide [26]. Using Bookin and Drits notation [30], we have also classified different types of stacking faults and observed that each type of stacking faults will significantly affect the peak shape of $(\mathrm{h} 0 \ell)$ reflections in nickel hydroxide. Generally, nickel hydroxide occurs in $1 \mathrm{H}$ polytype. The effect of $2 \mathrm{H}_{1}, 2 \mathrm{H}_{2}, 2 \mathrm{H}_{3}, 3 \mathrm{R}_{1}$, and $3 \mathrm{R}_{2}$ type of stacking faults in $1 \mathrm{H}$ polytype of nickel hydroxide has been extensively studied. The presence of $2 \mathrm{H}_{2}$ type of stacking faults in $1 \mathrm{H}$ polytype generates broad wings at the base and rises sharply as it approached maximum for (101) and (102) reflections, while incorporation of $3 R_{2}$ type of stacking faults in $1 \mathrm{H}$ polytype drastically affects (102) reflection. The FWHM values of all the peaks are listed in Table 4. In our earlier report, we have shown that the excessive and non-uniform broadening arises due to the presence of structural disorder [10]. To justify our hypothesis, we have simulated the PXRD pattern of $\beta_{\mathrm{bc}}$-nickel hydroxide by combining $23 \%$ interstratification, $20 \% 3 \mathrm{R}_{2}$ type of stacking faults, and $17 \%$ cation vacancies using DIFFaX code. The simulated PXRD pattern of $\beta_{\mathrm{bc}}$-nickel hydroxide is shown in Fig. 1 (as open circle with an $R_{\mathrm{wp}}$ value of $11.8 \%$ ). Figure $1 \mathrm{~b}$ shows the PXRD pattern of an ordered $\beta$-nickel hydroxide obtained on hydrothermal treatment of nickel hydroxide slurries at $170{ }^{\circ} \mathrm{C}$. Open circles in Fig. $1 \mathrm{~b}$ shows the simulated PXRD pattern of ordered $\beta$-nickel hydroxide with $4 \% 2 \mathrm{H}_{2}$ type of stacking faults and $3 \%$ cation vacancies with $R_{\mathrm{wp}}$ value of $10.2 \%$.

The electrochemical behaviour of $\beta_{\mathrm{bc}}$-nickel hydroxide with smaller crystallite size $(30 \times 254 \AA)$ and structural disorder differs from those of ordered crystalline $\beta$-nickel hydroxide with larger crystallite size $(674 \times 458 \AA)$ with low percentages of structural disorder. In Fig. $2 \mathrm{a}$, $\mathrm{i}$ and ii, are shown the cycle life data of $\beta_{\mathrm{bc}}$-nickel hydroxide and

Table 4 The full width at half maxima (FWHM in $2 \theta \pm 0.1^{\circ}$ ) of all the reflections in the PXRD patterns of the different $\beta_{\mathrm{bc}}$-nickel hydroxide samples

\begin{tabular}{|c|c|c|c|c|c|c|}
\hline Sample & $(001)$ & $(100)$ & $(101)$ & $(102)$ & $(110)$ & (111) \\
\hline$\beta_{\mathrm{bc}}$-Nickel hydroxide & 3.1 & 0.7 & 3.0 & Broad & 0.6 & 1.1 \\
\hline$\beta_{\mathrm{bc}}-\mathrm{Co}_{0.06}$ & 3.0 & 0.6 & 2.4 & Broad & 0.8 & 1.2 \\
\hline$\beta_{\mathrm{bc}}-\mathrm{Co}_{0.12}$ & 2.6 & 0.6 & 2.2 & Broad & 0.7 & 2.0 \\
\hline$\beta_{\mathrm{bc}}-\mathrm{Co}_{0.26}$ & 3.0 & 0.7 & 1.8 & Broad & 0.6 & 0.8 \\
\hline$\beta_{\mathrm{bc}}-\mathrm{Zn}_{0.15}$ & 1.9 & 0.5 & 1.0 & 2.0 & 0.6 & 0.7 \\
\hline$\beta_{\mathrm{bc}}-\mathrm{Zn}_{0.17}$ & 3.0 & 0.5 & 1.4 & 1.2 & 0.6 & 1.0 \\
\hline$\beta_{\mathrm{bc}}-\mathrm{Ca}_{0.06}$ & 3.1 & 0.7 & 1.9 & 2.3 & 0.9 & 1.2 \\
\hline$\beta_{\mathrm{bc}}-\mathrm{Cd}_{0.06}$ & 2.5 & 0.6 & 2.7 & Broad & 0.8 & 1.9 \\
\hline Sample & $(001)$ & $(100)$ & $(101)$ & $(102)$ & $(110)$ & $(111)$ \\
\hline$\beta$-nickel hydroxide & 0.3 & 0.3 & 0.4 & 0.4 & 0.4 & 0.4 \\
\hline$\beta-\mathrm{Co}_{0.05}$ & 0.3 & 0.3 & 0.3 & 0.4 & 0.3 & 0.4 \\
\hline$\beta-\mathrm{Zn}_{0.17}$ & 0.4 & 0.3 & 0.4 & 0.4 & 0.5 & 0.5 \\
\hline$\beta-\mathrm{Cd}_{0.05}$ & 0.33 & 0.4 & 0.5 & 0.6 & 0.5 & 0.6 \\
\hline
\end{tabular}




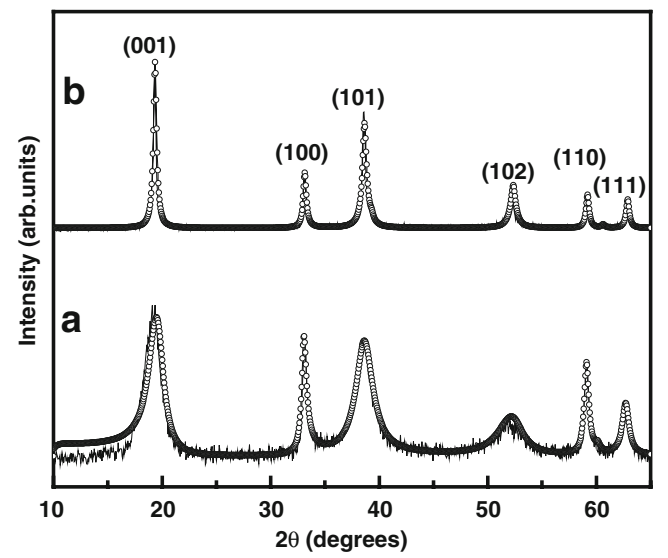

Fig. 1 Comparison of a observed PXRD pattern of $\beta_{b c}$-nickel hydroxide obtained at $80{ }^{\circ} \mathrm{C}$ with simulated PXRD pattern using $23 \%$ interstratification, $20 \% 3 \mathrm{R} 2$ stacking faults, and $17 \%$ cation vacancies (lower trace) and b observed PXRD pattern $\beta$-nickel hydroxide obtained at $170{ }^{\circ} \mathrm{C}$ with simulated PXRD pattern using $4 \%$ $2 \mathrm{H}_{2}$ and $3 \%$ cation vacancies (solid line observed; open circle simulated)

crystalline $\beta$-nickel hydroxide nickel hydroxide, respectively. It is clearly evident that $\beta_{\mathrm{bc}}$-nickel hydroxide with small crystallite size reversibly exchanges approximately close to $0.9 \mathrm{e} / \mathrm{Ni}$, while $\beta$-nickel hydroxide with larger crystallite size exchanges only $0.4 \mathrm{e} / \mathrm{Ni}$ (see Table 3 ).
We thought it would be interesting to investigate the electrochemical activities of substituted nickel hydroxide samples prepared under the same preparative conditions as that of $\beta_{\mathrm{bc}}$-nickel hydroxide, expecting a dramatic increase in its electrochemical performance as it is reported in the literature [11-18]. It would be ideal to compare the effect of substitution in nickel hydroxide with similar crystallite sizes. Table 3 gives the values of crystallite size of all substituted nickel hydroxide samples.

\section{Cobalt-substituted $\beta_{\mathrm{bc}}$-nickel hydroxide}

Cobalt-substituted $\beta_{\mathrm{bc}}$-nickel hydroxides was prepared by the addition of mixed metal nitrates solutions $\left[\mathrm{Ni}\left(\mathrm{NO}_{3}\right)_{2}\right.$ and $\mathrm{Co}\left(\mathrm{NO}_{3}\right)_{2}$ : mole ratios, 0.95:0.05, 0.90:0.1, and 0.8:0.2] to strong alkali at high $\mathrm{pH}>13\left(80^{\circ} \mathrm{C}\right)$. The actual chemical compositions of cobalt-substituted $\beta_{\mathrm{bc}}$-nickel hydroxides are given in Table 1. Pourbaix diagram indicates that coprecipitation of mixed metal salts with an appropriate mole ratio at a particular $\mathrm{pH}$ will not have the same mole ratio in the final product obtained. Figure 3 shows the PXRD patterns of 6, 12, and $26 \mathrm{~mol} \%$ (expected were 5,10 , and $20 \mathrm{~mol} \% \mathrm{Co}$ ). The PXRD patterns of cobalt-substituted $\beta_{\mathrm{bc}}$-nickel hydroxides display non-
Fig. 2 Cycle life data of electrodes comprising of sample a (i) $\beta_{\mathrm{bc}}$-nickel hydroxide obtained at $80{ }^{\circ} \mathrm{C}$ and (ii) $\beta$ nickel hydroxide obtained at $170{ }^{\circ} \mathrm{C}$, respectively; b (i) $6 \mathrm{~mol}$ $\%$, (ii) $12 \mathrm{~mol} \%$, and (iii) 26 mol\% cobalt-substituted $\beta_{\mathrm{bc}^{-}}$ nickel hydroxide electrodes; c

(i) $15 \mathrm{~mol} \%$, (ii) $17 \mathrm{~mol} \%$, and (iii) $18 \mathrm{~mol} \%$ zinc-substituted $\beta_{\mathrm{bc}}$-nickel hydroxide electrodes; d (i) $1 \mathrm{~mol} \%$ and (ii) $6 \mathrm{~mol} \%$ calcium-substituted $\beta_{\mathrm{bc}}$-nickel hydroxide electrodes; e $6 \mathrm{~mol} \%$ cadmium-substituted $\beta_{\mathrm{bc}}$-nickel hydroxide electrode; $\mathbf{f}(i)$ $5 \mathrm{~mol} \%$ cobalt-substituted $\beta$-nickel hydroxide electrode
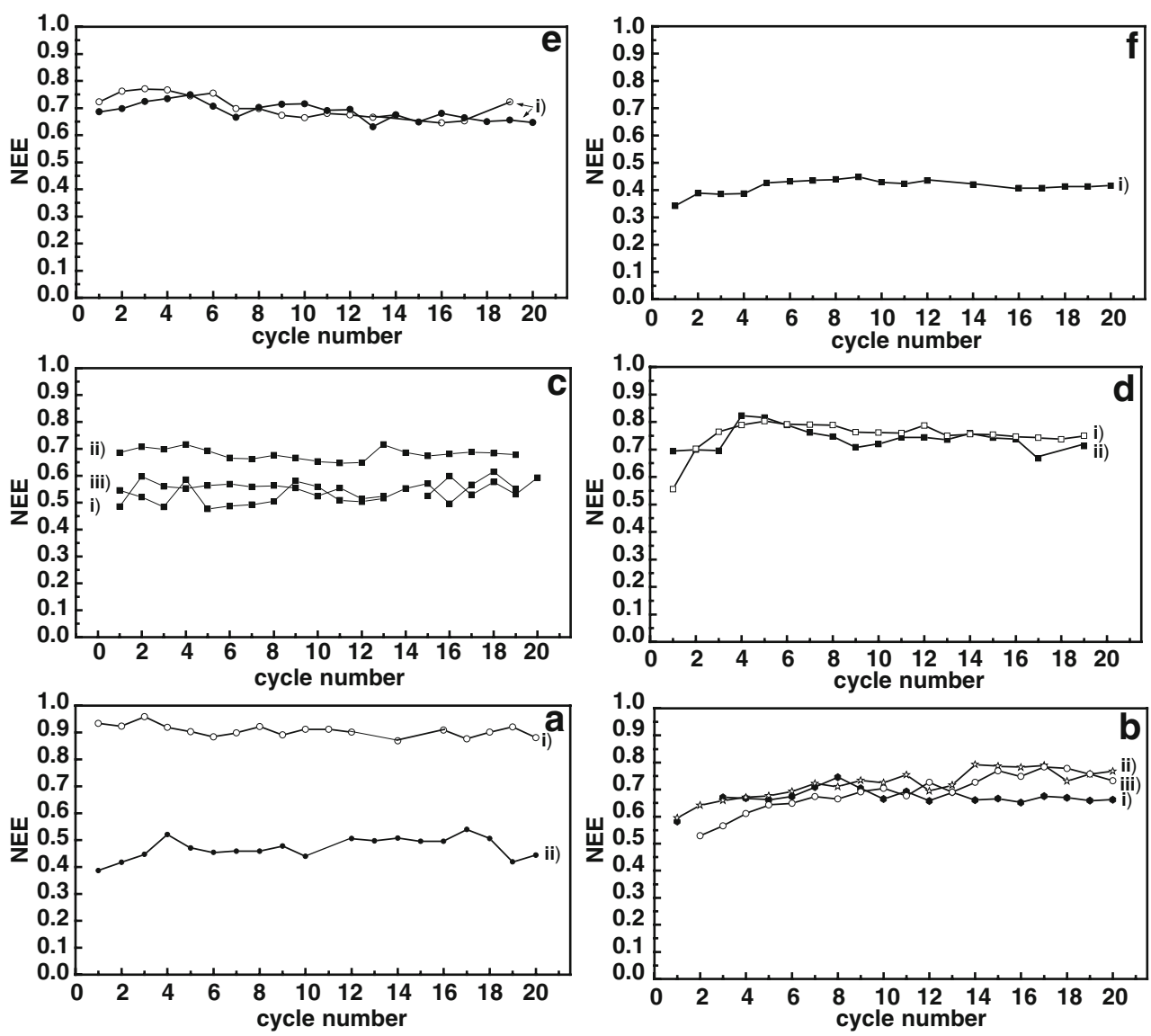


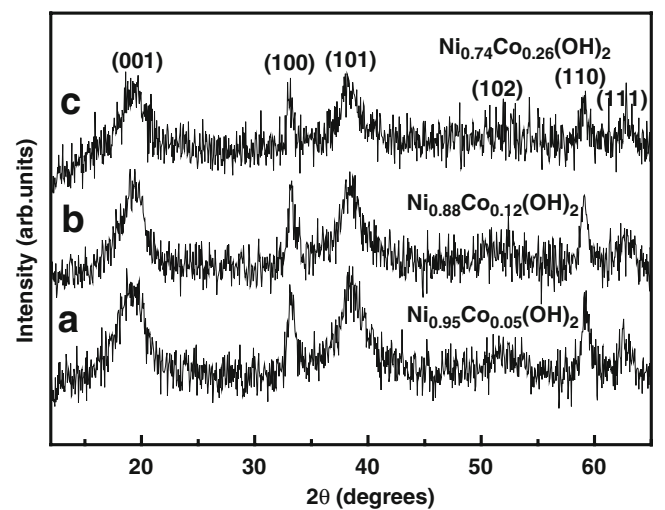

Fig. 3 PXRD patterns of a $6 \mathrm{~mol} \%, b 12 \mathrm{~mol} \%$, and c $26 \mathrm{~mol} \%$ cobalt-substituted $\beta_{\mathrm{bc}}$-nickel hydroxides, respectively

uniform broadening of non-(hk0) reflections similar to $\beta_{\mathrm{bc}^{-}}$ nickel hydroxide (see Fig. 1a). Partial substitution of cobalt in $\beta_{\mathrm{bc}}$-nickel hydroxide does not significantly affect the crystallinity and the broadening of non-(hk0) reflections in their PXRD patterns. In Tables 3 and 4 are given the crystallite size and FWHM values of all the reflections of cobalt-substituted $\beta_{\mathrm{bc}}$-nickel hydroxide samples, respectively. The crystallite sizes of $\beta_{\mathrm{bc}}$-nickel hydroxide and cobaltsubstituted $\beta_{\mathrm{bc}}$-nickel hydroxides are almost comparable. The beneficial effects of cobalt substitution are manifold: (1) It enhances the conductivity providing better chargeability for nickel hydroxide; (2) it lowers the oxygen evolution potential. There are reports that substitution of $8.5 \mathrm{~mol} \%$ cobalt in nickel hydroxide shows dramatic improvement in the electrochemical property [17]. When cobalt-substituted $\beta_{\mathrm{bc}}$-nickel hydroxide is charged, $\mathrm{Co}^{2+}$ gets oxidized to either $\mathrm{Co}^{3+} / \mathrm{Co}^{3.7+}$ oxidation states, and during discharge, it gets reduced to $\mathrm{Co}^{3+}$ reamin in $3+$ state. During this process, (1) composition of the sample changes from $\mathrm{Ni}_{1-x} \mathrm{Co}_{x}(\mathrm{OH})_{2}$ to $\mathrm{Ni}_{1-\mathrm{x}}^{2+} \mathrm{Co}_{x}^{3+}(\mathrm{OH})_{2-x}\left(\mathrm{CO}_{3}\right)_{x / n}^{n-} \cdot \mathrm{H}_{2} \mathrm{O}$, resulting in the formation of layered double hydroxide, and (2) $\mathrm{Co}^{3+} / \mathrm{Co}^{3.7+}$ redox couple during the charge-discharge process can also contribute to the charge storage capacity of nickel hydroxide, thereby misleading it to the enhancement in the electrochemical activity of nickel hydroxide [31]. Earlier work from our laboratory have shown that layered double hydroxide $\left[\mathrm{Ni}_{0.8} \mathrm{Al}_{0.2}(\mathrm{OH})_{2-x}\left(\mathrm{CO}_{3}\right)_{x / n} \cdot x \mathrm{H}_{2} \mathrm{O}\right]$ exchanges $1.7 \mathrm{e} / \mathrm{Ni}$ [32]. The above factors are responsible for delivering $>1 \mathrm{e}$ exchange in cobalt-substituted nickel hydroxides and nickel hydroxides with cobalt as additive, thereby misleading it to the effect of cobalt contribution to the enhancement in the electrochemical activity of nickel hydroxide [33]. Even though substitution of cobalt in $\beta_{\mathrm{bc}}$-nickel hydroxide does not affect the crystallite size and the reflections in their PXRD pattern significantly, we expected that cobalt could still contribute to the electrochemical property of the material based on the literature reports. Figure $2 b$, i-iii, shows the cycle life data of 6,12 , and $26 \mathrm{~mol} \%$ cobalt-substituted $\beta_{\mathrm{bc}^{-}}$ nickel hydroxide electrodes. We expected a drastic change in the electrochemical performance of cobalt-substituted nickel hydroxide, but the results shows that it exchanges $0.65-0.7 \mathrm{e} /$ $\mathrm{Ni}$, which is slightly lower than that of $\beta_{\mathrm{bc}}$-nickel hydroxide. The results clearly indicate when the crystallite sizes are similar; substitution of cobalt into nickel hydroxide matrix does not enhance the electrochemical performance of $\beta_{\mathrm{bc}}{ }^{-}$ nickel hydroxide electrode.

\section{Zinc-substituted $\beta_{\mathrm{bc}}$-nickel hydroxide}

Zinc-substituted $\beta_{\mathrm{bc}}$-nickel hydroxides was prepared by the addition of mixed metal nitrates solutions $\left[\mathrm{Ni}\left(\mathrm{NO}_{3}\right)_{2}\right.$ and $\mathrm{Zn}\left(\mathrm{NO}_{3}\right)_{2}$ : mole ratios, $0.85: 0.15$ and $\left.0.8: 0.2\right]$ to strong alkali at high $\mathrm{pH}>13\left(80{ }^{\circ} \mathrm{C}\right)$. The actual chemical compositions of zinc-substituted $\beta_{\mathrm{bc}}$-nickel hydroxides are given in Table 1. Figure 4 shows the PXRD patterns of 15 and $18 \mathrm{~mol} \%$ (expected 15 and $20 \mathrm{~mol} \%$ ) zinc-substituted $\beta_{\mathrm{bc}}$-nickel hydroxide. Tables 3 and 4 show the crystallite size and the FWHM for these samples. The non-uniform broadening of reflections in the PXRD patterns of zincsubstituted $\beta_{\mathrm{bc}}$-nickel hydroxide remain unchanged. Substitution of higher zinc content (>15 mol\%) in the nickel hydroxide matrix, results in the changes in the peak shape of $(\mathrm{h} 0 \varrho$ ) reflections to a flaring of wings at the bottom and narrowing as it approaches peak maximum. Delmas and coworkers have extensively studied the electrochemical performance of zinc-substituted nickel hydroxide by varying the experimental conditions during precipitation [34]. They relate this type of peak shape to the presence of stacking faults. We classify it to the $2 \mathrm{H}_{2}$ type of stacking faults for zinc-substituted $\beta_{\mathrm{bc}}$-nickel hydroxide. Figure 2c, $\mathrm{i}$, ii, and iii, shows the cycle life data of 15,17 , and $18 \mathrm{~mol} \%$ zinc-substituted $\beta_{\mathrm{bc}}$-nickel hydroxide samples. The chemical composition of all the samples was different from that of the expected due to the presence of lower nickel content in the samples. The reversible discharge capacity decreases from $0.9 \mathrm{e} / \mathrm{Ni}$ in $\beta_{\mathrm{bc}}$-nickel hydroxide to $0.65-0.55 \mathrm{e} / \mathrm{Ni}$ in zincsubstituted $\beta_{\mathrm{bc}}$-nickel hydroxide.

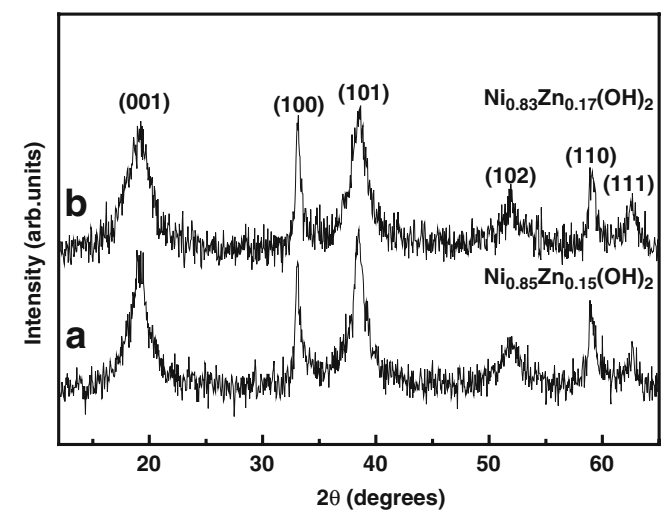

Fig. 4 PXRD patterns of $a 15 \mathrm{~mol} \%$ and $b 17 \mathrm{~mol} \%$ zinc-substituted $\beta_{\mathrm{bc}}$-nickel hydroxides 


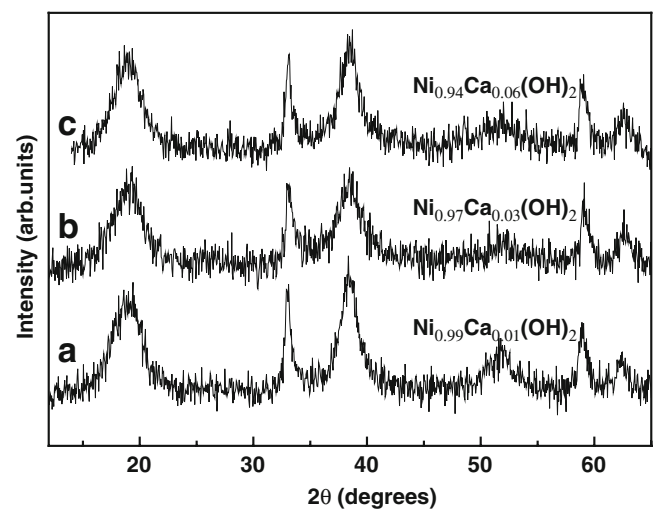

Fig. 5 PXRD patterns of 1,3 , and 6 mol $\%$ calcium-substituted $\beta_{\mathrm{bc}^{-}}$ nickel hydroxides, respectively

Calcium-substituted $\beta_{\mathrm{bc}}$-nickel hydroxide

Calcium-substituted $\beta_{\mathrm{bc}}$-nickel hydroxides was prepared by the addition of mixed metal nitrates solutions $\left[\mathrm{Ni}\left(\mathrm{NO}_{3}\right)_{2}\right.$ and $\mathrm{Ca}\left(\mathrm{NO}_{3}\right)_{2}$ : mole ratios, 0.95:0.05, 0.90:0.10, and 0.85:0.15] to strong alkali at high $\mathrm{pH}>13\left(80^{\circ} \mathrm{C}\right)$. The actual chemical composition of calcium-substituted $\beta_{\mathrm{bc}}$-nickel hydroxide is given in Table 1. Figure 5 shows the PXRD patterns of calcium-substituted nickel hydroxide with $x=0.01,0.03$, and 0.06 (expected 5, 10, and $15 \mathrm{~mol} \% \mathrm{Ca}$ ), respectively. Chemical analysis shows that calcium does not get incorporated within the nickel hydroxide matrix due to its larger size. Tables 3 and 4 give the crystallite size and the FWHM values of calcium-substituted $\beta_{\mathrm{bc}}$-nickel hydroxide sample. The PXRD patterns of all the samples are nonuniformly broadened and have similar crystallite size. Figure $2 \mathrm{~d}, \mathrm{i}$ and ii, shows the cycle life data of $x=0.01$ and $0.06 \mathrm{~mol} \%$ calcium-substituted $\beta_{\mathrm{bc}}$-nickel hydroxide samples. Calcium-substituted $\beta_{\mathrm{bc}}$-nickel hydroxide samples delivers $0.7-0.76 \mathrm{e} / \mathrm{Ni}$.

Cadmium-substituted $\beta_{\text {bc }}$-nickel hydroxide

Cadmium-substituted $\beta_{\mathrm{bc}}$-nickel hydroxides was prepared by the addition of mixed metal nitrates solutions $\left[\mathrm{Ni}\left(\mathrm{NO}_{3}\right)_{2}\right.$

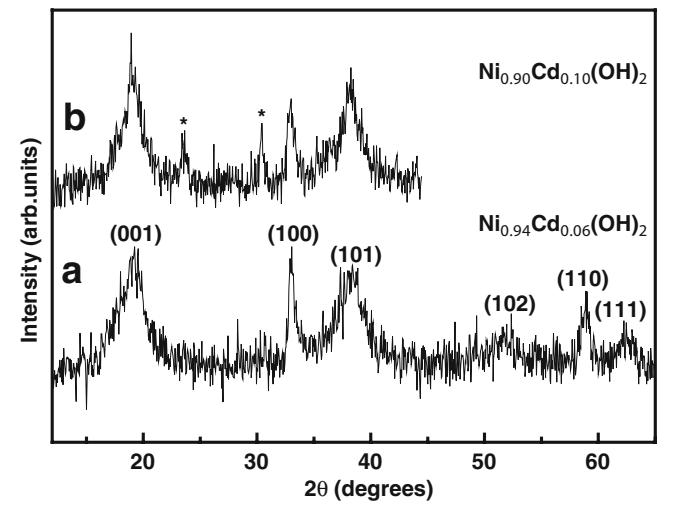

Fig. 6 PXRD patterns of a $6 \mathrm{~mol} \%$ and $b \quad 10 \mathrm{~mol} \%$ cadmiumsubstituted $\beta_{\mathrm{bc}}$-nickel hydroxides. The asterisk indicates impure phase

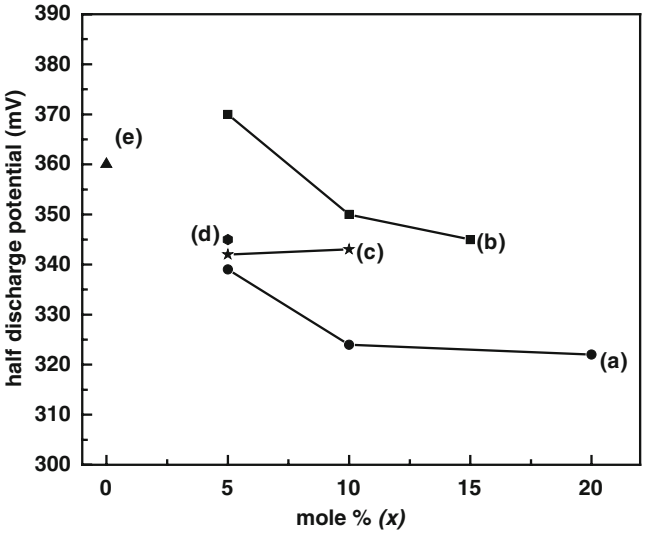

Fig. 7 The half discharge potential of $\beta_{\mathrm{bc}}$-type substituted nickel hydroxides as a function of $x \mathrm{~mol} \%$ for $a x=0.06,0.12,0.15$, and 0.26 of cobalt; $b x=0.15$ and 0.17 of zinc; $c x=0.01,0.03$, and 0.06 of calcium; $d x=0.06$ of cadmium; and $e \beta_{\mathrm{bc}}$-nickel hydroxide electrodes

and $\mathrm{Ca}\left(\mathrm{NO}_{3}\right)_{2} ;$ mole ratios, 0.95:0.05, 0.90:0.10, and $0.8: 0.2]$ to strong alkali at high $\mathrm{pH}>13\left(80^{\circ} \mathrm{C}\right)$. The actual chemical composition of cadmium-substituted $\beta_{\mathrm{bc}}$-nickel hydroxide is given in Table 1. Figure 6 shows the PXRD patterns of cadmium-substituted $\beta_{\mathrm{bc}}$-nickel hydroxide with $x=0.06$ and 0.1 (expected 0.05 and $0.10 \mathrm{~mol} \% \mathrm{Cd}$ ), respectively. At $x=0.1, \mathrm{CdO}$ phase is also observed in the PXRD pattern due to the phase segregation. The ionic radii of the cadmium ion are bigger than the size of the octahedral vacant site; hence, biphasic mixture was observed in cadmium-substituted $\beta_{\mathrm{bc}}$-nickel hydroxide samples. Table 4 provides the FWHM of $x=0.06$ composition. The PXRD patterns show that substitution of cadmium in $\beta_{\mathrm{bc}}$-nickel hydroxide matrix does not significantly influence the characteristic feature of non-uniform broadening. Figure 2e shows the cycle life data of cadmium-substituted $\beta_{\mathrm{bc}}$-nickel hydroxide, which exchanges $0.7 \mathrm{e} / \mathrm{Ni}$.

Figure 7 shows the variation of half discharge potentials as a function of ' $x$ ' for substituted $\beta_{\mathrm{bc}}$-nickel hydroxide electrodes and unsubstituted $\beta_{\mathrm{bc}}$-nickel hydroxide. Substi-

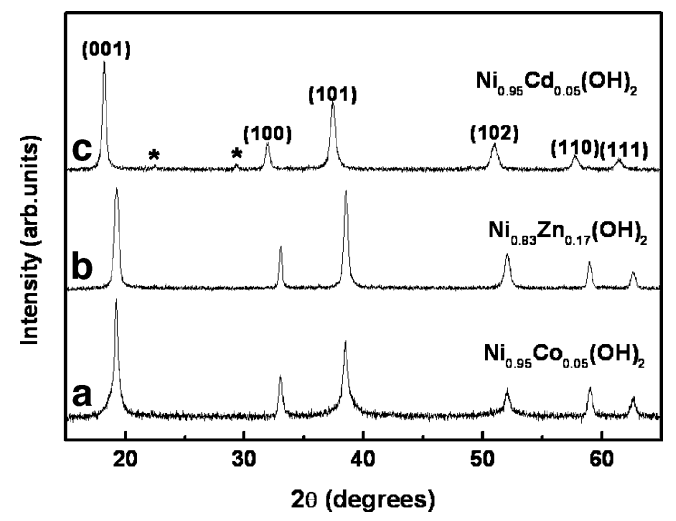

Fig. 8 PXRD patterns of a $5 \mathrm{~mol} \%$ cobalt, $b 17 \mathrm{~mol} \%$ zinc, and $c$ $5 \mathrm{~mol} \%$ cadmium-substituted $\beta$-nickel hydroxide obtained by hydrothermal treatment at $170{ }^{\circ} \mathrm{C}$. The asterisk indicates impure phase 
tution of other divalent metal ions affects the oxygen evolution potential without affecting the electrochemical performance. Similar results were also reported in the literature $[35,36]$.

Cobalt/zinc/cadmium-substituted crystalline $\beta$-nickel hydroxide

Figure 8 shows the PXRD patterns of $5 \mathrm{~mol} \%$ cobalt, $17 \mathrm{~mol} \%$ zinc, and $5 \mathrm{~mol} \%$ cadmium (expected $5 \mathrm{~mol} \%$ cobalt, $10 \mathrm{~mol} \%$ zinc, and $5 \mathrm{~mol} \%$ cadmium)-substituted $\beta$ nickel hydroxides obtained on hydrothermal treatment at $170{ }^{\circ} \mathrm{C}$ for $18 \mathrm{~h}$ separately. The PXRD patterns in Fig. 8 were compared with that of crystalline $\beta$-nickel hydroxide (see Fig. 1b). The broadening of reflections in the PXRD pattern of substituted crystalline $\beta$-nickel hydroxide and the crystallite sizes are similar to that of crystalline $\beta$-nickel hydroxide. If the substituents play a crucial role in influencing electrochemical activity, then it should significantly affect the electrochemical performance of a substituted crystalline $\beta$-nickel hydroxide with larger crystallite size. In Fig. 2f, i, is shown the cycle life data of $5 \mathrm{~mol} \%$ cobalt-substituted $\beta$-nickel hydroxide. The cobalt-substituted $\beta$-nickel hydroxide exchanges $0.4 \mathrm{e} / \mathrm{Ni}$, and the value is similar to the values of crystalline $\beta$-nickel hydroxide. Zinc-substituted $\beta$-nickel hydroxide electrode failed to deliver electrochemical activity, while cadmium-substituted $\beta$-nickel hydroxide shows very weak additional reflections in the PXRD pattern due to the formation of $\mathrm{CdO}$ impurities.

Deabate and coworkers also show that the presence of substituents can inhibit the diffusion of protons [36]. Substitution of other divalent metal ions in nickel hydroxide matrix will only affect the charge-discharge plateau potential and oxygen evolution potential. Smaller crystallite size with structural disorder is the critical determinant for better electrochemical activity.

\section{Conclusions}

The electrochemical charge-discharge process in nickel hydroxide involves intercalation and deintercalation of protons within the layers. Several factors can affect the diffusion of protons in nickel hydroxide. In this article, we have focused on the structural aspects of the substituted nickel hydroxide samples and its influence of electrochemical behaviour. The electrochemical activity is better in $\beta_{\mathrm{bc}^{-}}$ nickel hydroxide having structural disorder with smaller crystallite size. The divalent metal-substituted $\beta_{\mathrm{bc}}$-nickel hydroxide samples with structural disorder and smaller crystallite size perform lower than the unsubstituted $\beta_{\mathrm{bc}^{-}}$ nickel hydroxide. Substitution in crystalline $\beta$-nickel hydroxide with larger crystallite size does not enhance the electrochemical performance. The presence of structural disorder with smaller crystallite size provides a good pathway for electrochemical activity and is the key determining factor for high electrochemical performance and not due to the presence of substituents. Thus, $\beta_{\mathrm{bc}^{-}}$ nickel hydroxide is an ideal choice as electrode material at ambient conditions $\left(25-30{ }^{\circ} \mathrm{C}\right)$.

Acknowledgment T.N.R thanks the Council of Scientific and Industrial Research, GOI, for the award of Senior Research Fellowship (NET) and Research Associate fellowship. P.V.K. thanks the Department of Science and Technology, Government of India (GOI), for financial support. He is a recipient of the Ramanna Fellowship. Authors thank the Solid State and Structural Chemistry Unit of the Indian Institute of Science for powder X-ray diffraction facilities.

\section{References}

1. Falk SU, Salkind AJ (1969) Alkaline storage batteries. Wiley, New York

2. Faure C, Delmas C, Fouassier C (1991) J Power Sources 35:279

3. Oswald HR, Asper R (1977) In: Lieth RMA (ed) In bivalent metal hydroxides, vol 1. D Reidel Publishing, Holland, p 71

4. Bode H, Dehmelt K, Witte J (1966) Electrochim Acta 11:1079

5. Audemer A, Delahaye-Vidal A, Farhi R, Sa-Epee N, Tarascon J-M (1997) J Electrochem Soc 144:2614

6. Jayashree RS, Kamath PV, Subbanna GN (2000) J Electrochem Soc 147:2029

7. Hui L, Yunchang D, Jiongliang Y, Zeyun W (1995) J Power Sources 57:137

8. Ramesh TN, Jayashree RS, Kamath PV (2003) J Electrochem Soc 150:520

9. Bernard R, Randell C, Tye FL (1981) Power sources, vol. 8. Academic, London, p 401

10. Ramesh TN, Kamath PV, Shivakumara C (2005) J Electrochem Soc 152:806

11. Tessier C, Faure C, Guerlou-Demourgues L, Denage C, Nabias G, Delmas C (2002) J Electrochem Soc 149:1136

12. Constantin DM, Rus EM, Oniciu L, Ghergari L (1988) J Power Sources 74:188

13. Oshitani M, Sasaki Y, Takashima K (1984) J Power Sources 12:219

14. Pickett DF, Maloy JT (1978) J Electrochem Soc 125:1026

15. Pralong V, Chabre Y, Delahaye-Vidal A, Tarascon J-M (2002) Solid State Ionics 147:73

16. Oshitani M, Yufu H, Takashima K, Tsuji S, Matasumaru Y (1989) J Electrochem Soc 136:1590

17. Pralog V, Delahaye-Vidal A, Beaudoin B, Gerand B, Leriche JB, Tarascon J-M (2000) J Electrochem Soc 147:1306

18. Fierro C, Zallen A, Koch J, Fetchenko MA (2006) J Electrochem Soc 153:492

19. Jun L, Rong L, Hang S (1999) J Power Sources 79:86

20. Yuan AB, Chang SA, Zhang JQ, Cao CN (1999) J Power Sources $77: 178$

21. Yuan AB, Xu NX (2001) J Appl Electrochem 31:45

22. Oshitani M, Watada M, Shodai K, Kodama M (2001) J Electrochem Soc 148:67

23. Ramesh TN, Kamath PV, Shivakumara C (2006) Acta Crystallogr B 62:530 
24. Cornilsen BC, Shan X, Loyselle PL (1990) J Power Sources 29:453

25. Bernard MC, Cortes R, Keddam M, Takenouti H, Bernard P, Senyarich S (1996) J Power Sources 63:247

26. Delmas C, Tessier C (1997) J Mater Chem 7:1439

27. Warren BE, Bodenstein P (1966) Acta Crystallogr 20:602

28. Rajamathi M, Kamath PV, Seshadri R (2000) J Mater Chem 10:503

29. Radha AV, Kamath PV, Shivakumara C (2007) Acta Crystallogr B 63:243

30. Bookin AS, Drits VA (1993) Clays Clay Miner 41:551

31. Faure C, Delmas D, Willmann P (1991) J Power Sources 35:249
32. Kamath PV, Dixit M, Indira L, Shukla AK, Kumar VG, Munichandraiah N (1994) J Electrochem Soc 141:2956

33. Audemer A, Delahaye A, Farhi R, Sac-Epée N, Tarascon J-M (1997) J Electrochem Soc 144:2614

34. Tessier C, Guerlou-Demourgues L, Faure C, Basterreix M, Nabias G, Delmas C (2000) Solid State Ionics 133:11

35. Casas-Cabanas M, Rodriguez-Carvajal J, Canales-Vazques J, Rose Placin M (2006) J Mater Chem 16:2925

36. Deabate S, Henn F, Devautour S, Giuntini JC (2003) J Electrochem Soc 150:23 